\title{
The Enhancing and Intermediating Effects of a Gratitude Course among Nursing Students
}

\author{
$\mathrm{Ju}$-Eun Hong $^{1}$ and Myeongkyeong Song ${ }^{2 *}$ \\ ${ }^{1}$ Professor, Department of Nursing Science, Dongyang University, 145, \\ Dongyangdae-ro, Punggi-eup, Yeongju-si, Gyeongsangbuk-do, Republic of Korea \\ ${ }^{2}$ Professor, Department of Nursing Science, Andong Science College, 189, Seoseon- \\ gil, Seohu-myeon, Andong-si, Gyeongsangbuk-do, Republic of Korea \\ ${ }^{1}$ nurse0413@dyu.ac.kr, ${ }^{2}$ songmirror@asc.ac.kr
}

\begin{abstract}
A partially investigational study, this paper is aimed at determining the effects of a gratitude course on nursing undergraduates' gratitude temperament and subjective satisfaction. It was conducted among 54 freshmen and sophomores majoring in nursing, with a six-session gratitude program applied to the experimental group. At this juncture, gratitude temperament and subjective happiness improved significantly after the program was run, and gratitude disposition carried on throughout the six months after the program. Concisely, a gratitude program contributes to an improvement in gratitude disposition and subjective happiness in nursing students.
\end{abstract}

Keywords: Nursing student, Gratitude, Happiness, Program

\section{Introduction}

\subsection{Need for study}

In South Korea, the demand for nurses has recently been on the rise with the constant surge in the nursing service demand due to the aging population and the changing healthcare environment [1]. An increasing number of students apply to the Department of Nursing, regardless of gender, because of the ease of getting a job, compared with other majors, and the relatively high level of wage [2]. However, because nursing students are required to possess various qualifications as healthcare providers, they tend to bear greater difficulties in campus life, compared with students from other majors [2].

Gratitude is a feeling typical of optimistic human beings [3] and one of the emotions frequently felt and expressed daily [4]. It can be said that gratitude is a useful concept especially for nursing students because it reportedly reduces negative emotions [5] and strongly affects anger control [6][7]. However, intervention programs for nursing students have been limited to key skills, patients and caregivers, communication interdisciplinary cooperation [8], and capability reinforcement [9], which are primarily associated with clinical nursing; thus, it is necessary to develop a program based on the understanding of the emotional experiences of nursing students, to improve positive emotions among them. This

Article History:

Received (November 3, 2019), Review Result (December 17, 2019), Accepted (January 22, 2020) 
study has developed a gratitude program, taking into account the finding of the literature review that gratitude disposition affects subjective satisfaction among nursing undergraduates [10], in keeping with the conceptual probing, identifying the characteristics of gratitude and emotional experience [2] among nursing students [5]. It likewise aims to develop and apply a gratitude program reflecting the emotions of nursing students, playing the leading role in future clinical sites, and determining the program's effects on their subjective happiness.

\subsection{Purpose}

This study seeks to develop and apply a gratitude program and determine its effects on the gratitude mentality and subjective satisfaction among nursing students.

\section{Methods}

\subsection{Study design}

Partially experimental research, this paper is designed at determining the effects of a gratitude course on gratitude temperament and individual satisfaction among nursing students.

\subsection{Subject and ethical consideration}

This study underwent a research ethics review at D University (1041495-201703-HR-0401), followed by a relevant officer's written consent, before it started. G*Power indicated the target group size of 26 students. 27 students were randomly sampled firstly in the experimental and control groups, discounting the dropouts. Finally, 24 participated in the experimental group and 26 in the control group the inquiry.

\subsection{Instruments}

\subsubsection{Gratitude disposition}

The Korean rendering of the Gratitude Questionnaire-6 (GQ-6), conceived by McCullough et al. (2002) [11] and translated by Kwon, Kim, and Lee [12], was used. Cronbach's $\alpha$ was estimated at .813 for reliability in this experiment.

\subsubsection{Subjective happiness}

The Subjective Happiness Scale (SHS), initiated by Lyubomirsky and Lepper (1999) [13] and translated and validated by Kim (2007) [14], was employed. In this study, Cronbach's $\alpha$ was estimated at .737 for reliability.

\subsection{Program development and running}

The gratitude program was developed through a literature review regarding adolescents' emotional experiences and emotional management based on the conceptual analysis of "gratitude." The program was run in the experimental group - for about 60 to 90 minutes per session - and the abbreviated program was provided to the control group after the study for ethical deliberation in addition to gratitude for research participation.

In running the program, each session involved reflection on the previous session and climate creation through a "presentation" of a "gratitude journal" before it started, followed 
by guidance about the current session, thematic activity, and consolidation. Session 1 was directed to explain the purpose and progression of the program, let the participants greet one another, and allow them to perform a pretest. Session 2 intended to promote self-awareness and conduct the activity of "self-auction," to recognize their values. Session 3 sought to recollect and relieve the feeling and situations of their own "anger" and share impressions and cases. Session 4, Gratitude Awareness and Expression, endeavored to perform a role play related to a grateful situation. Session 5, Habit Formation for Emotional Management Skills, permitted participants to practice expressing gratitude, experience its positive effects, be motivated, and take part in a completion ceremony in the last session.

\subsection{Data collection}

Data were collected from April to May 2018, while a pretest was performed in Session 1 and a post-test was performed in Session 6 when the program ended.

\subsection{Data analysis}

The gathered data were scrutinized through the $\chi 2$-test, Fisher's exact test, independent ttest, and paired t-test upon employment of the SPSS 24.0 program.

\section{Results}

\subsection{Participants' homogeneity test}

The experimental and control groups were uniform, with the homogeneity test ascertaining no statistically noteworthy inter-group disparity in any of the wide-ranging attributes and such dependent variables as gratitude disposition and subjective happiness [Table 1].

Table 1 . Homogeneity assay on general attributes and conditional variables

\begin{tabular}{|c|c|c|c|c|c|c|c|c|c|}
\hline \multirow{2}{*}{\multicolumn{2}{|c|}{ Division }} & \multicolumn{3}{|c|}{ The experimental group $(n=24)$} & \multicolumn{3}{|c|}{ Control group $(n=26)$} & \multirow{3}{*}{$\begin{array}{l}\mathrm{t} \\
-\end{array}$} & \multirow{3}{*}{$\frac{p \text {-value }}{.103 \dagger}$} \\
\hline & & \multirow{2}{*}{$\mathrm{n}$} & \multirow{2}{*}{$(\%)$} & \multirow{2}{*}{$\begin{array}{c}\mathrm{M} \pm \mathrm{SD} \\
19.67 \pm 1.58\end{array}$} & \multirow{2}{*}{$\mathrm{n}$} & \multirow{2}{*}{$(\%)$} & \multirow{2}{*}{$\begin{array}{c}\mathrm{M} \pm \mathrm{SD} \\
20.96 \pm 3.50\end{array}$} & & \\
\hline Age & & & & & & & & & \\
\hline \multirow{4}{*}{ Religion } & Protestant & 3 & $(12.5)$ & - & 7 & $(26.9)$ & - & \multirow{4}{*}{-} & \multirow{4}{*}{$.343 *$} \\
\hline & Buddhist & 1 & $(4.2)$ & - & 3 & $(11.5)$ & - & & \\
\hline & Catholic & 1 & $(4.2)$ & - & 2 & (7.7) & - & & \\
\hline & Other & 19 & $(79.2)$ & - & 14 & $(53.8)$ & - & & \\
\hline \multirow{2}{*}{$\begin{array}{l}\text { Living with } \\
\text { parents }\end{array}$} & Yes & 21 & $(87.5)$ & - & 22 & $(84.6)$ & - & \multirow{2}{*}{-} & \multirow{2}{*}{$1.000 *$} \\
\hline & No & 3 & $(12.5)$ & - & 4 & $(15.4)$ & - & & \\
\hline \multirow{3}{*}{$\begin{array}{c}\text { Major } \\
\text { satisfaction }\end{array}$} & $\begin{array}{c}\text { Very } \\
\text { satisfied }\end{array}$ & 7 & $(29.2)$ & - & 4 & $(15.4)$ & - & \multirow{3}{*}{-} & \multirow{3}{*}{$.159 *$} \\
\hline & satisfied & 14 & $(58.3)$ & - & 13 & $(50.0)$ & - & & \\
\hline & Average & 3 & $(12.5)$ & - & 9 & $(34.6)$ & - & & \\
\hline \multirow{3}{*}{$\begin{array}{l}\text { Self-rated } \\
\text { health }\end{array}$} & Good & 14 & $(58.3)$ & - & 9 & $(34.6)$ & - & \multirow{3}{*}{-} & \multirow{3}{*}{$.078^{*}$} \\
\hline & Average & 10 & (41.7) & - & 13 & $(50.0)$ & - & & \\
\hline & $\mathrm{Bad}$ & 0 & $(.0)$ & - & 4 & $(15.4)$ & - & & \\
\hline \multirow{3}{*}{$\begin{array}{c}\text { Financial } \\
\text { level }\end{array}$} & High & 4 & $(16.7)$ & - & 2 & $(7.7)$ & - & \multirow{3}{*}{ - } & \multirow{3}{*}{$.501 *$} \\
\hline & Medium & 17 & $(70.8)$ & - & 16 & (61.5) & - & & \\
\hline & Low & 3 & $(12.5)$ & - & 8 & $(30.8)$ & - & & \\
\hline
\end{tabular}




\begin{tabular}{|c|c|c|c|c|c|c|c|c|c|}
\hline $\begin{array}{c}\text { Gratitude } \\
\text { disposition }\end{array}$ & & - & - & $30.92 \pm 4.70$ & - & - & $30.69 \pm 5.75$ & .150 & $.881 \dagger$ \\
\hline $\begin{array}{c}\text { Subjective } \\
\text { happiness }\end{array}$ & & - & - & $24.33 \pm 3.74$ & - & - & $24.08 \pm 4.57$ & .216 & $.830 \dagger$ \\
\hline
\end{tabular}

F: t test, *:Fisher's exact test

\subsection{Effect test of the gratitude program}

H1. The experimental group participating in the gratitude program would see their gratitude temperament and subjective satisfaction surge vis-a-vis the control group.

The experimental group registered a substantially higher tally for gratitude temperament and subjective satisfaction than the control group [Table 2].

Table 2. Changes in scores for gratitude temperament and subjective satisfaction in the experimental and control groups

\begin{tabular}{|c|c|c|c|c|c|}
\hline \multicolumn{2}{|c|}{ Division } & Pretest & Post-test & \multirow{2}{*}{$\mathrm{t}$} & \multirow{2}{*}{ p-value } \\
\cline { 3 - 5 } & $\mathrm{M} \pm \mathrm{SD}$ & $\mathrm{M} \pm \mathrm{SD}$ & & \multirow{2}{*}{.000} \\
\hline \multirow{3}{*}{ Gratitude disposition } & $\begin{array}{c}\text { The experimental group } \\
(\mathrm{n}=24)\end{array}$ & $30.92 \pm 4.70$ & $36.29 \pm 4.36$ & -5.245 & .558 \\
\cline { 2 - 5 } & Control group (n=26) & $30.69 \pm 5.75$ & $30.04 \pm 5.01$ & .593 & .000 \\
\hline \multirow{2}{*}{ Subjective happiness } & $\begin{array}{c}\text { The experimental group } \\
(\mathrm{n}=24)\end{array}$ & $24.33 \pm 3.74$ & $27.54 \pm 3.60$ & -4.866 & .000 \\
\cline { 2 - 4 } & Control group (n=26) & $24.08 \pm 4.57$ & $23.00 \pm 3.31$ & 1.697 & .102 \\
\hline
\end{tabular}

H2. The experimental group participating in the gratitude program would see the effectiveness in improving gratitude disposition and subjective happiness persist six months following the course.

The experimental group scored significantly higher for gratitude disposition six months after the trial of the program than prior one's partaking, evidencing no considerable variance in subjective satisfaction between six months after the conclusion of the program and before participation in the program [Table 3].

Table 3. Changes in scores for gratitude disposition and subjective happiness among pretest, post-test, and follow-up in the experimental group

\begin{tabular}{|c|c|c|c|c|c|c|c|}
\hline \multirow{2}{*}{ Division } & Pretest & Post-test & Follow-up & \multicolumn{2}{|c|}{ Post-test and follow-up } & \multicolumn{2}{|c|}{ Pretest and follow-up } \\
\cline { 2 - 8 } & $\mathrm{M} \pm \mathrm{SD}$ & $\mathrm{M} \pm \mathrm{SD}$ & $\mathrm{M} \pm \mathrm{SD}$ & $\mathrm{T}$ & $\mathrm{p}$-value & $\mathrm{t}$ & $\mathrm{p}$-value \\
\hline $\begin{array}{c}\text { Gratitude } \\
\text { disposition }\end{array}$ & $30.92 \pm 4.70$ & $36.29 \pm 4.36$ & $33.79 \pm 6.03$ & 1.830 & .080 & -2.076 & .049 \\
\hline $\begin{array}{c}\text { Subjective } \\
\text { happiness }\end{array}$ & $24.33 \pm 3.74$ & $27.54 \pm 3.60$ & $25.67 \pm 4.30$ & 1.771 & .090 & -1.630 & .117 \\
\hline
\end{tabular}

\section{Discussion}

The experimental group participating in the gratitude program scored significantly higher for gratitude disposition after running the program (36.29) than before running the program (30.92). This result is coherent with the discovery that university undergraduates performed substantially higher in the gratitude disposition score after the gratitude program [4]. The control group scored lower for gratitude disposition after the program, suggesting the need for 
continuous stimulation through the intentional activity because gratitude disposition can be reduced by personal and environmental factors.

This study tried to be differentiated from most of the previous studies by determining if the effects of gratitude disposition remained six months after the application of the gratitude program, verifying if the effects persisted six months after the conclusion of the course given that the gratitude course constructed and applied in this study helped form a habit through an improvement in gratitude disposition and the daily practice of gratitude based on the properties of gratitude [5]. The experimental group experienced subjective happiness statistically, and this significantly improved after the experiment compared with the control group. The improvement in subjective happiness is significantly meaningful to nursing students, who will be at the forefront of others' healthcare after graduation. Hong and Song [2] reported that nursing students experienced anxiety and stress due to a tight daily life in studying nursing and had negative emotions, such as academic stress, anger, depression, and difficulty in emotional control, due to the curriculum that combined theoretical lectures and clinical training [15][16]. Therefore, nursing students are more likely to require a gratitude program that can reduce negative emotions and improve positive ones.

\section{Conclusion}

This is a partially experimental probe that verifies the influence of a gratitude program on gratitude temperament and subjective satisfaction among nursing undergraduates. In summary, a gratitude program contributes to an improvement in gratitude disposition and subjective satisfaction among nursing undergraduates and is expected to provide useful data for their emotional management.

\section{Acknowledgment}

This experiment was assisted by the Research Program to Solve Social Issues of the National Research Foundation of Korea (NRF) subsidized by the Ministry of Science and ICT (No. 2017R1C1B1005347).

\section{References}

[1] "Ministry of education. opportunity to become a nurse is expanded by major category (sub-category)," [Internet], Sejong: Ministry of Education; $\quad$ [cited $2018 \quad$ Sep. http://www.moe.go.kr/boardCnts/view.do?boardID=294\&boardSeq=75430\&lev=0\&searchType $=$ $\mathrm{S} \&$ status $Y N=W \&$ page $=1 \& s=$ moe $\& \mathrm{~m}=0503 \&$ opType $=\mathrm{N},(\mathbf{2 0 1 8})$

[2] Hong JE and Song MK, "Emotional experiences of nursing student's college life," Journal of Korean Academy of Psychiatric and Mental Health Nursing. (KPMHN), vol.3, no.5, pp.163-275, (2019)

[3] Peterson B. E. and Seligman M. E. P., "Character strengths and virtues: A handbook and classification," New York: Oxford University Press, (2004)

[4] Moon EJ, "Gratitude program development for college students," The Korean Journal of School Psychology., vol.11, no.3, pp.541-562, (2014)

[5] Hong JE and Lee JS, "Concept analysis of gratitude," Journal of Korean Academy Psychiatric Mental Health Nursing. (JKPMHN), vol.23, no.4, pp.298-309, (2014)

[6] Jun WH, "Trait anger, anger expression, positive thinking and gratitude in college students," Journal of Korean Academy of Psychiatric and Mental Health Nursing. (JKPMHN), vol.25, no.1, pp.28-36, (2016) 
[7] Emmons RA and McCuuough ME, "Counting blessing verse burdens: An experimental investigation of gratitude and subjective well-being in daily life," Journal of Personality and Social Psychology, vol.84, no.2, pp.377-389, (2003)

[8] Ha IK, "Curriculum integration of communication simulation to community health nursing course for nursing students: a pilot study," Journal of the Korea Academia-Industrial cooperation Society. (KAIS), vol.16, no.4, pp.2329-2337, (2015)

[9] Park AY and Kim KH, "Development and evaluation of competency-based quality improvement and safety education program for undergraduate nursing students,” Korean Journal of Adult Nursing. (KJAN), vol.25, no.5, pp.559-571, (2016)

[10] Jun WH, Lee SY, and Lee KL, "Mediating effect of gratitude on the relationship between life stress and depression," Journal of Korean Public Health Nursing, (JKPHN), vol.31, no.3, pp.528-539, (2017)

[11] McCullough M. E., Tsang J., and Emmons R. A., "The grateful disposition: a conceptual and empirical topography," Journal of Personality and Social Psychology, no.82, pp.112-127, (2002)

[12] Kwon SJ, Kim KH, and Lee HS, "Validation of the Korea version of gratitude questionnaire," The Korean Journal of Health Psychology. (J HEALTH PSYCHOL), no.11, pp.177-190, (2006)

[13] Lyubomirsky S. and Lepper H. S., “A measure of subjective happiness: Preliminary reliability and construct validation," Social Indicators Research, no.46, pp.137-155

[14] Kim HJ, "A study on the relationships among positive affects, subjective happiness, and school adjustment," The graduate school of Chungnam University. A master's thesis, (2007)

[15] Reeve K. L., Shumakera C. J., Yearwood E. L., Crowell N. A., and Riley J. B., Perceived stress and social support in undergraduate nursing students' educational experiences. Nurse Education Today. (JNEDT), (2012), no.33, pp.419-424, (2013)

[16] [Choi YS, Lee EJ, and Lee DH, "Relationship of locus of control, difficulties in emotion regulation, and clinical practice stress,” Journal of The Korea Contents Association, vol.18, no.1, pp.540-550, (2018) 